\title{
Catherine Dixon
}

\section{Describing typeforms: a designer's response}

\author{
Type design, classification, lettering, typography
}

\begin{abstract}
The paper sets out an overview of a pragmatic research investigation initiated within a doctoral enquiry, and which continues to inform design practice and pedagogy. Located within the fields of typography and information design, and very much concerned with design history, enquiry emphasized exploration of alternative design research methodologies in the production of a design outcome loaded with pedagogical ambition.

The issue being addressed within the investigation was the limited scope of existing typeface classificatory systems to adequately describe the diversity of forms represented within current type design practice and thus, recent acquisitions to an established teaching collection in London.

Addressing this issue unexpectedly came to utilize the researcher's own design practice as a methodology for managing emergent enquiry, and for organizing and generating new knowledge through the employment of visual information management methods.

A primary outcome of the enquiry was a new framework for the description of typeforms. This new framework will be described in terms of its operation, divergence from existing models and potential for application.
\end{abstract}

\section{Introductory context}

The initial context for enquiry was a photographic lettering collection known as The Central Lettering Record (CLR). This collection was begun in the 1960s and comprises 10,000 photographs and some 4,000 slides, all housed as part of the teaching materials for the BA (Hons) Graphic Design course at Central Saint Martins College of Art \& Design, London [Baines \& Dixon 2004].

As a collection the CLR is very much informed by practice. It documents lettering practice of all eras and kinds; content is structured using practice-methods and was largely determined by a practitioner - originated by Nicholas Biddulph in 1963 it was the lettering practitioner and scholar Nicolete Gray who later drove the scope of the collection forward. The collection was also set up for the benefit of practice, to be used by practitioners and designers (as well as historians and other academics) for the purposes of enriching understanding and moving forward existing ideas within the lettering field.

In 1994 I was working with the CLR as the Research Student for an umbrella college research project entitled, 'Interactive multimedia: creative uses of interface design for typographic research' [Kindel 1996]. My task was to update the CLR particularly in terms of its representation of typeface design and I set about collecting examples of font specimens from the previous 10-15 years. This material then had to be catalogued alongside the older historical typeface material for input into a newly created database. The database required a series of descriptive fields for types both new and old based upon their visual appearance, or, as Sutton \& Bartram describe, as 'typeforms' [Sutton \& Bartram 1968].

Common practice then determined that the generic description of typeforms should utilize the category terms borrowed from classification schemes. The scheme selected for application was the British Standard for typeface classification and nomenclature, BS 2961 from 1967 [British Standards Institution 1967]. And while it may seem strange to have turned to a classification then nearly 30 years old, the BS was technically still 'current' (revision of this standard was scheduled for 1981 but postponed) and, along with the Vox system [Vox 1954] from which it is derived, typical and very much still in circulation in the UK [McLean 1988, Carter 1995, Blackwell 1998]

\section{Issue}

The BS schema operates by differentiating types using a series of category terms: humanist, 
garalde, transitional, didone, slab-serif, lineale (grotesque, neo-grotesque, geometric, humanist), glyphic, script, graphic. Definitions for each term summarise shared configurations of particular formal attributes, such as serif detailing, construction, shape and so on. Each of the identified categories acts as a 'container' in which types can be located and thus described.

Through application of the BS category terms it became clear that they were not able to satisfactorily differentiate between the necessary breadth of forms represented by contemporary typefaces and thus, the recent acquisitions to the CLR collection. Too much of the newer material could only be accommodated within the 'graphic' category. This is defined as being for those, 'typefaces whose characters suggest that they have been drawn rather than written, for example Libra, Cartoon and Monotype Old English' [British Standards Institution 1967]. Yet, this purposefully open-ended definition, which allows the category to act as a classificatory 'catch-net' makes little visual sense of the diverse range of typeforms caught. While accommodated or classified here, typeforms are not actually being described.

\section{As Walter Tracy argued of the British Standard,}

'The classification is not all-embracing, though. Originality does flourish, even in such a crowded field. It must be allowed that any type which cannot be classified at all is probably so distinctive as to demand special description, like the duck-billed platypus.' [Tracy 1971]

The difficulty with this view is the change in scale of type design output since it was written. Headline film-setting and transfer lettering had already begun the process of revalidating the commercial expediency of formal experimentation within type design. Digital technologies of the later part of the twentieth century allowed for acceleration of this process, further facilitating formal fragmentation, increasing accessibility to type design software and dispersing centres of type production. Combined with the outworkings of what Robert Bringhurst describes as, the 'surfeit of historical awareness and self-mockery' symptomatic 'of the phase we call postmodernism' this resulted in a resurgence of interest in hybrid forms, with designers intentionally avoiding existing pigeon-holes and plundering and reconfiguring elements from an ever-widening range of sources [Bringhurst 1994].

There was growing recognition that the existing universal classifications were failing to address the significant shifts in type design practice but the ease of continuing with the familiar, if faulty, schemas often outweighed the upheaval change would necessitate. Certainly a case was argued for their simplicity, albeit flawed [Sauthoff, Wendt \& Willberg 1997]. In defence of his use of the open-ended typeface category term 'decorative' (effectively in place of 'graphic') Lewis Blackwell acknowledges that,

'It sounds like a loose term, and it is - but how do we describe the rapidly increasing number of fonts that do not draw on one particular historical tradition or form of production, but are distinguished by being sports that draw on the varied visual culture of their time.' [Blackwell 1998]

For some, it seemed acceptable to retain classificatory structures that excluded this new dimension of practice. The direction in the pursuit of formal novelty has sometimes proved so controversial as to call into question whether such types should even be acknowledged, let alone afforded descriptive attention. Lawrence Wallis perhaps voiced the opinions of a more traditional generation, when he complained,

'So much contemporary type design seems to be irrelevant, trivial, fatuous, flippant, clamourous, straining for effect and novelty, illegible, gimmicky, quirky and worthless.' [Wallis 1994]

For myself working within the broad collection remit of the CLR I could not indulge such a qualitative view. Nor would I have wished to. The failure to incorporate such types within historical surveys has created in many key texts the sense of an artificial endpoint in typeform history, with much contemporary practice entirely dislocated from that of the past [Lawson 1990, Bartram \& Dowding 1998, Heller \& Fink 1997].

A number of new proposals were though being made. And interestingly, it was the prompt of the increased individuality of typeform in the 1990s to which many seemed to respond [Bauermeister 1994, Mundie 1995]. Within these systems, such is the emphasis upon the individual typeface, however, that formal description can tend towards the abstract

Certainly within the description remit of the CLR catalogue none of the more recent proposals were either timely or appropriate. That is not to say that any of these systems or even the BS and Vox systems are wrong per se. As Bringhurst observes, 'no system of classification is flat-out correct', therefore no one system of classification is flat-out incorrect [Bringhurst 1994]. Rather, a number of systems may be useful with the measure of usefulness being entirely dependent upon what it is you require or need a given system to do. 
It was really at this point that my own PhD enquiry begins to distinguish itself from the work I was undertaking as a Research Student for the umbrella Interactive multimedia project. As a result of the early cataloguing difficulties experienced within the CLR, an hypothesis was formulated that a large and growing number of recent typeforms could not be described nor appropriately located within existing frameworks.

The main aims and objectives of enquiry were to investigate this hypothesis and if found to be true, to explore a vocabulary of terms and phrases able to describe contemporary typeforms. Further, the research sought to establish a description framework capable of:

- locating these recent developments within an historical overview of typeface design in an attempt to overcome the fracture prevalent in discourse.

- consistently describing the formal character of Western typefaces across an approximately 550 year production period. (In broad terms, the formal character of a typeface was understood as being how the punchcutter or designer intended it to be seen in use.)

- communicating type description information in a non-abstract way facilitating accessibility for users both familiar and unfamiliar with type (in keeping with the practice emphasis and pedagogical interests of the original CLR context and in recognition of the fact that the mathematical encoding of digital types is in itself a kind of formal description language.)

While it was intended that the results of my PhD enquiry would feed back into the CLR database work, the research was not directed towards producing a typeform description framework for only that purpose. So while the critical stance brought to the field of typeform description owed much to the CLR it was never constrained by the requirements of the database context alone. Nonetheless balancing the demands of the ongoing Interactive multimedia project against my own doctoral research was not always straightforward. It was clear, for example, that an alternative response to typeform description was needed but my early work towards this was heavily framed by the schedule of the Interactive multimedia project with poor results.

Perpetuating the 'make do and mend' philosophy, which had come to dominate the classificatory field, I returned to the BS, and adopted the simplest strategy of trying to modify the existing categorization structure. The contents of the overloaded 'graphic'/ junkbox category were dispersed across a series of newly added categories. However, an emphasis on modifying only one category resulted in failure. Even the work directed towards the consistent expansion of definitions across all the categories could not disguise the fact that the problems of the scheme were not confined to one part. The structure overall was flawed with no even basis for categorical division. The instability of the whole only became more obvious in the process of trying to build into it.

My findings to that point were published along with a working proposal for a revised categorization [Dixon 1995] Of no lasting value in itself, this early proposal did come to represent a turning point in the enquiry. Two key areas were highlighted for evaluation - categorisation and visual presentation.

The work extending the existing schema showed that the widespread 'top-down' approach to categorisation could not provide a long term solution to the existing description difficulties posed by the ever-broadening range of sources utilised by type designers. The extra categories initially proposed scarcely scratched the surface of the problem. Yet to increase the number added would lead to an unwieldy system: too many categories each with too few typefaces. Acceleration in the field of typeface design/production means that to keep a system up-to-date would anyway be impossible [see the ambitious but quickly outdated system in Perfect \& Kono 1983]. The inevitable shortfall in categories leaves typeforms beyond classification, and so the original problem remains.

Nor could categorisation offer a practical or sustainable response to the hybridization of form characteristic of much recent practice. Even the combined application of category terms (as suggested by both Vox and in the original BS guidelines to ensure optimum classificatory scope) could not introduce enough detailed flexibility to cope with the increased emphasis on typeform individuality.

It was in many ways, however, the visual presentation of my early work as published, which confirmed my suspicions of categorization as an invalid description strategy for typeforms. The regimented series of uniform boxes representing the working category terms belied the complexities of the narratives actually underpinning the categorization (Figure 1). While the objective of the description system was to bring order to chaos - not just reflect it - a more accurate visual presentation of these narratives would, I had felt, encourage the subtlety of description required. In the hands of a remote graphic designer my tentative thoughts and ideas had been subjected to some design-tidying. 'Sans serif problems' was never intended as a 
category, more a note to myself that this was an area needing work.

I realized the need to take control myself of the visual presentation of my research work and the importance of visuals more generally in the communication of classificatory argument. And so I began a process of attempting to visually map the stories informing the existing categorization structures utilizing my own design practice.

Figure 1: illustration accompanying my working proposal for a revised set of typeform categories, designed and published by Eye magazine in 1995

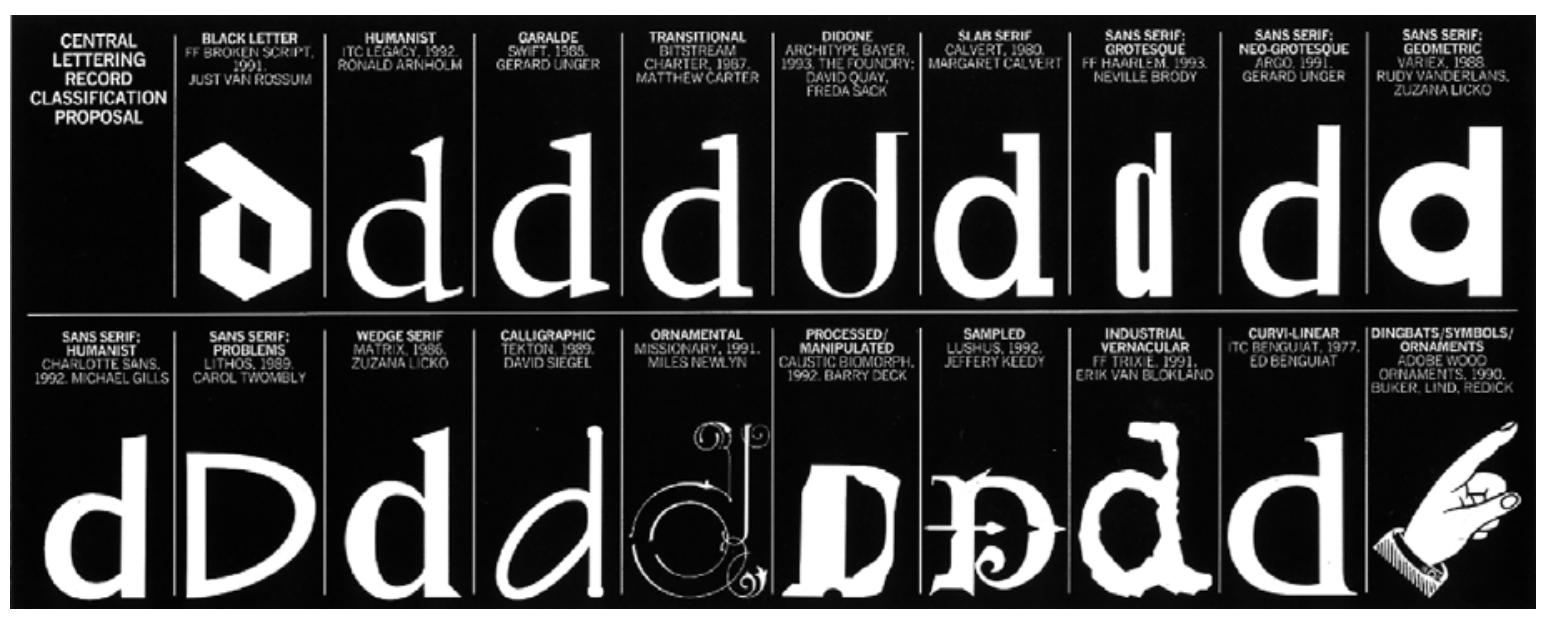

\section{Design practice}

Re-evaluation of the role of visual presentation in type classification is entirely consistent with past practice, which determined extensive historical precedent for visual classificatory argument. Basic visual methods were in use in some of the earliest formal systems. In the 1903 system devised by French typographer Thibaudeau for the historic material of the Peignot foundry and the system devised between 1911-12 by H L Bullen, librarian for the American Typefounders (ATF) are found the first of the more analytical typeform classifications [Bullen 1911, Thibaudeau 1924]. Both systems share a structural approach based upon serif differentiation. Both systems also introduce a new consideration of presentation. Thibaudeau's system although unremarkable in its limited scope, is significant in terms of its visual emphasis. Thibaudeau's tabular approach enables him to present his system as a whole, summarising in this one illustration the full extent of the system and its organizational principles.

Beatrice Warde advanced Bullen's 'morphological' ideas concerning the organization of typeforms, setting out her 1935 classification according to evolutionary principles [Warde 1935]. Although a 'selective' classification in that it only deals with book types the visual presentation of her system not only sets out the principles of arrangement but also establishes the hierarchical relationship of these principles. Significantly, in terms of the development of my own framework, Warde's emphasis on representing description principles, which though sometimes employing exising category terms are never illustrated by sample types, means that the precise location of a given typeface within her system is only ever implicit. It is not made explicit through the containment of actual types within her diagrammatic overview.

Warde's hierarchical advancements in the mapping of classificatory information were followed by Jan Tschichold and Rudolf Hostettler. They both set out in many ways less sophisticated though still complex relational hierarchies of category terms (illustrated using exemplary types) within historical frameworks [Tschichold 1946; 1952, Hostettler 1949]. Hostettler's typeform map, as used in his 1949 book Type doesn't do anything to address any of the key categorization issues I have outlined, but it is wonderful to look at (Figure 2). And though such a purely aesthetic view was largely qualitatively irrelevant there was something about the ability of this visually rich representation to provoke wonder I found of value. There is also something reassuring - if potentially misleading - about the sense of order communicated in the telling of a complex story. 


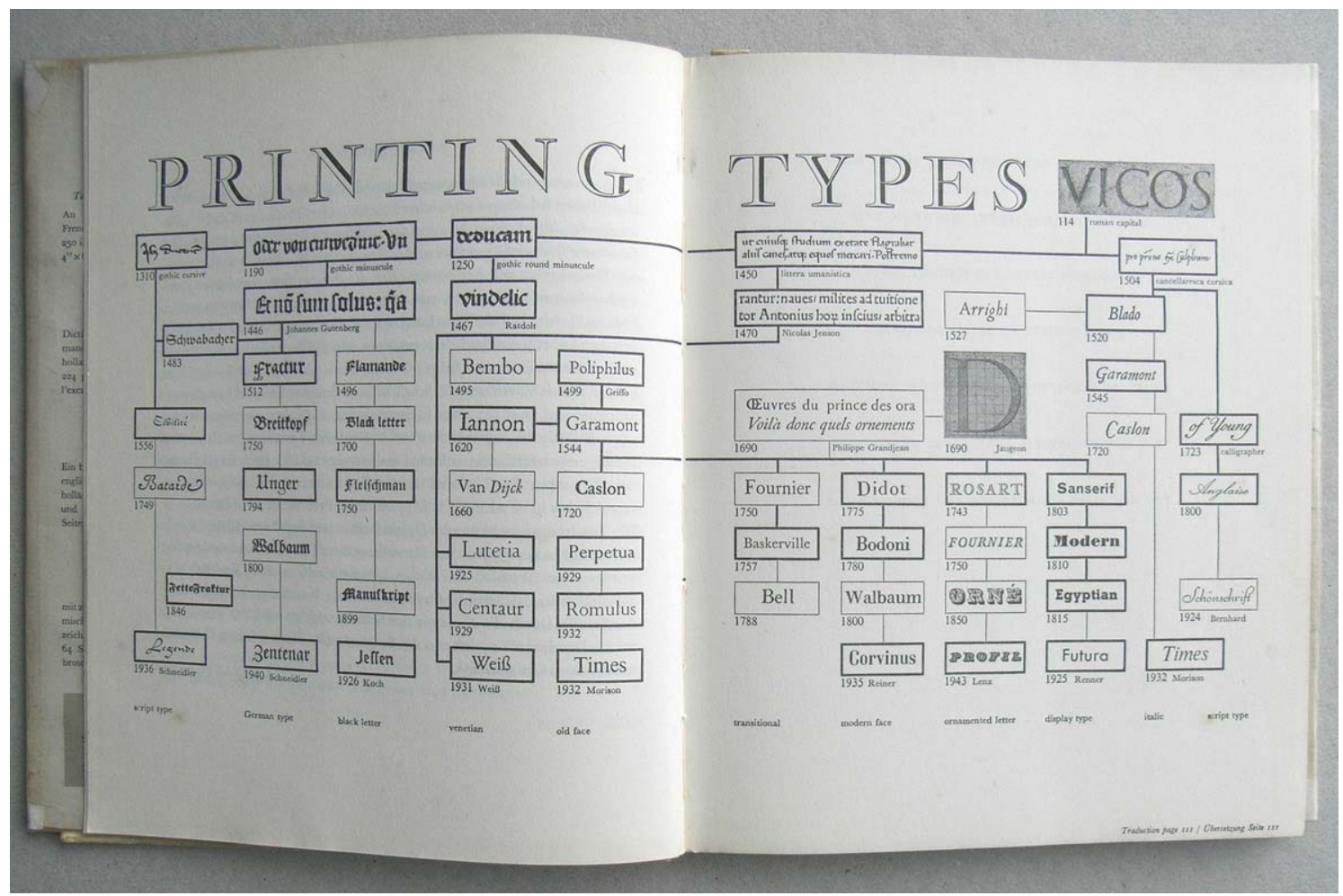

And of course, there are many other examples, though the Hostettler serves as a good point to introduce my own visual re-evaluations. Dissatisfaction with the uneven basis for categorical division in my working categorization proposal (analyzed in detail elsewhere, see Dixon 2002) led to my identifying hierarchical and structural relationships between categories. Underlying design narratives were located which informed the grouping of sets of categories. These generic groupings for categories (later identified as 'sources') describe the structural rationale for a types appearance. Early exercises in mapping categories as they articulate the development of the design narratives underpinning these generic structural typeform groupings, led to the formulation of a diagrammatic schema for the chronological representation of type design history.

A chronological representation worked well until it came to incorporating the developments of the nineteenth century. The diversification characteristic of a broader commercialism in the field and the fracture in the relationship between time and the introduction of typeforms prompted by the formal revivalism of this period proved difficult to map alongside the history of type design as it had evolved up until that point. Visual methods were used as a means of further subject analysis to gain a more precise understanding of the nature of the formal diversification at work during the nineteenth century. Typeface samples referred to in Gray's Nineteenth century ornamented typefaces [Gray 1938/1976] were, for example, formally clustered and chronologically represented on a timeline so I could more clearly identify typeform progressions (Figure 3).

It was found that the lifting and mixing of formal elements from type design sources, so often attributed as an outcome of digital type design practices, was in fact neither transitory or new. Gray's detailed study of Nineteenth century ornamented typefaces reveals the origins of this 'new freedom' in the introduction of the continental Latin-Runic typefaces, commenting that,

'although so far no very drastic changes have been made, categories are becoming blurred and classification complicated; a new era has begun'. [Gray 1976] 
Figure 3: visual analysis methods employed in the analysis of types from the nineteenth century using collage and drawing to determine formal and chronological type sample clusters

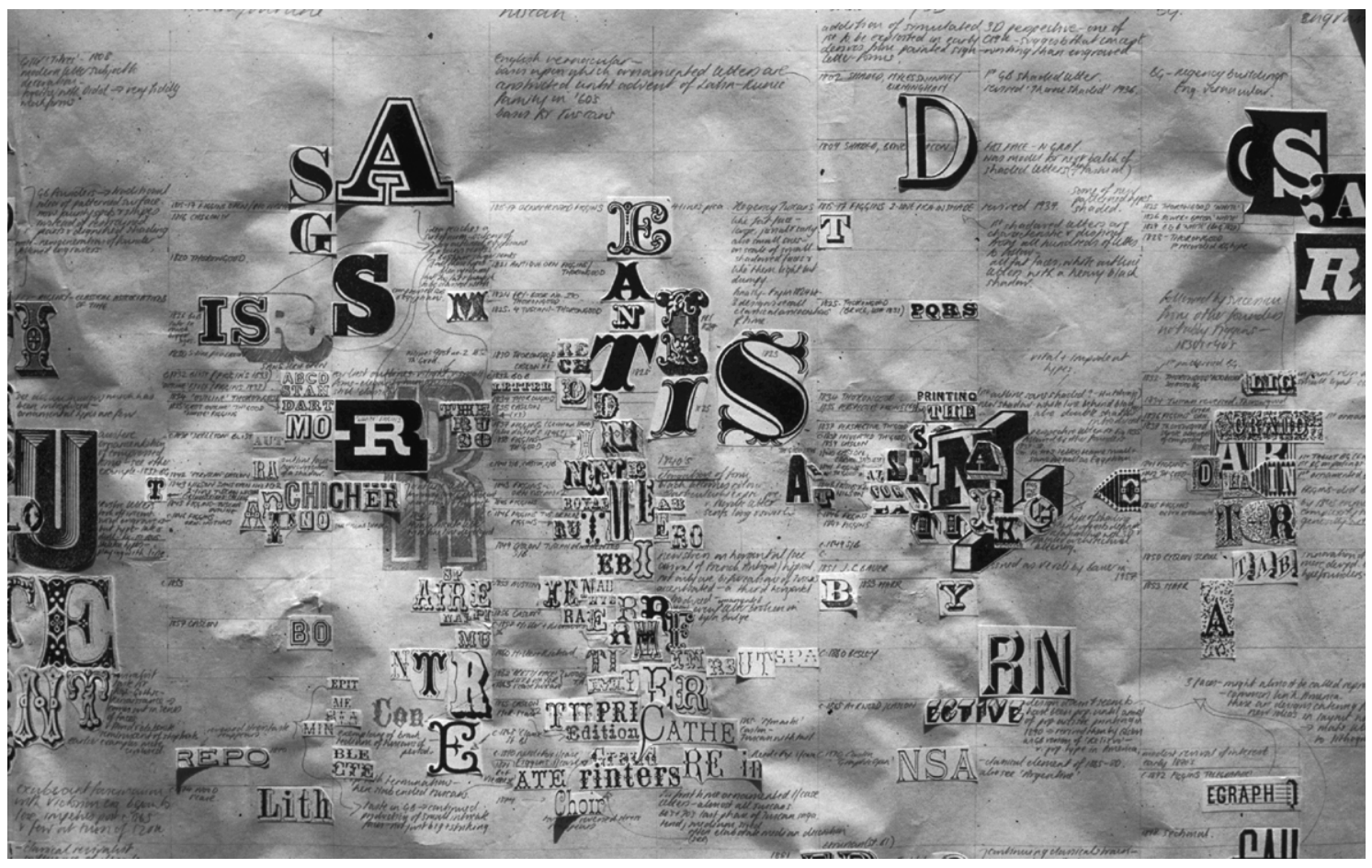

As Gray intimates however, the infinitely variable possibilities promoted by this reconfiguration process are singularly at odds with a means of describing typeforms that uses only a limited number of headings. Design practice previously convergent around established 'patterns' for typeforms becomes increasingly divergent. Attempts to visually resolve representation of this fracture in the field revealed that the set combinations of formal attributes, which had defined earlier typeform patterns exploded. Attributes of form were freed from their existing fixed associations and reconfigured in the establishment of new typeform patterns.

Identification of a greater fragmentation of formal ideas in the field was crucial in shifting emphasis away from a category-driven approach to typeform description towards the formulation of a more organic system comprising a series of description components from which descriptions could be created for types on an individual basis. Visual methods were again used in the analysis of the identified patterns for typeforms to establish the range of formal attributes in circulation. At this stage work on the chronological representation of type design history shifted to a visual mapping of the relationships between each of the different identified description components as a new framework began to take shape.

\section{Outcome}

The nascent description framework was tested and refined through application within a digital typeform interrogation environment which had been developed concurrently by members of the orginal umbrella Interactive multimedia research project. Part of the testing process required the delivery of consistent and accessible descriptions of 140 typeforms selected to represent the diversity of practice in Western type design since the introduction of moveable printing type - in keeping with the original ambitions for a new framework outcome.

The new description framework operates through utilization of three description components, identified as 'sources', 'formal attributes' and 'patterns'.

Sources describe the generic structural influences and rationales informing a typeform. Their identification, as described previously, grew out of the analysis of the larger groups into which existing classificatory categories could be ordered: roman, handwritten and so on.

Formal attributes are the basic individual units of description that refer to a typeface's design and construction. These were identified by exploding into individual units of description the previously 
grouped physical characteristics determining the categories. Eight main kinds of these attributes were identified - construction, shape, proportion, modelling, weight, terminals, key characters and decoration - each of these with a further sub-menu of its own. As a set of illustrated terms they serve as a visual glossary explaining the practice vocabulary of type design (Figure 4, see also Baines \& Haslam 2005, 50-2)

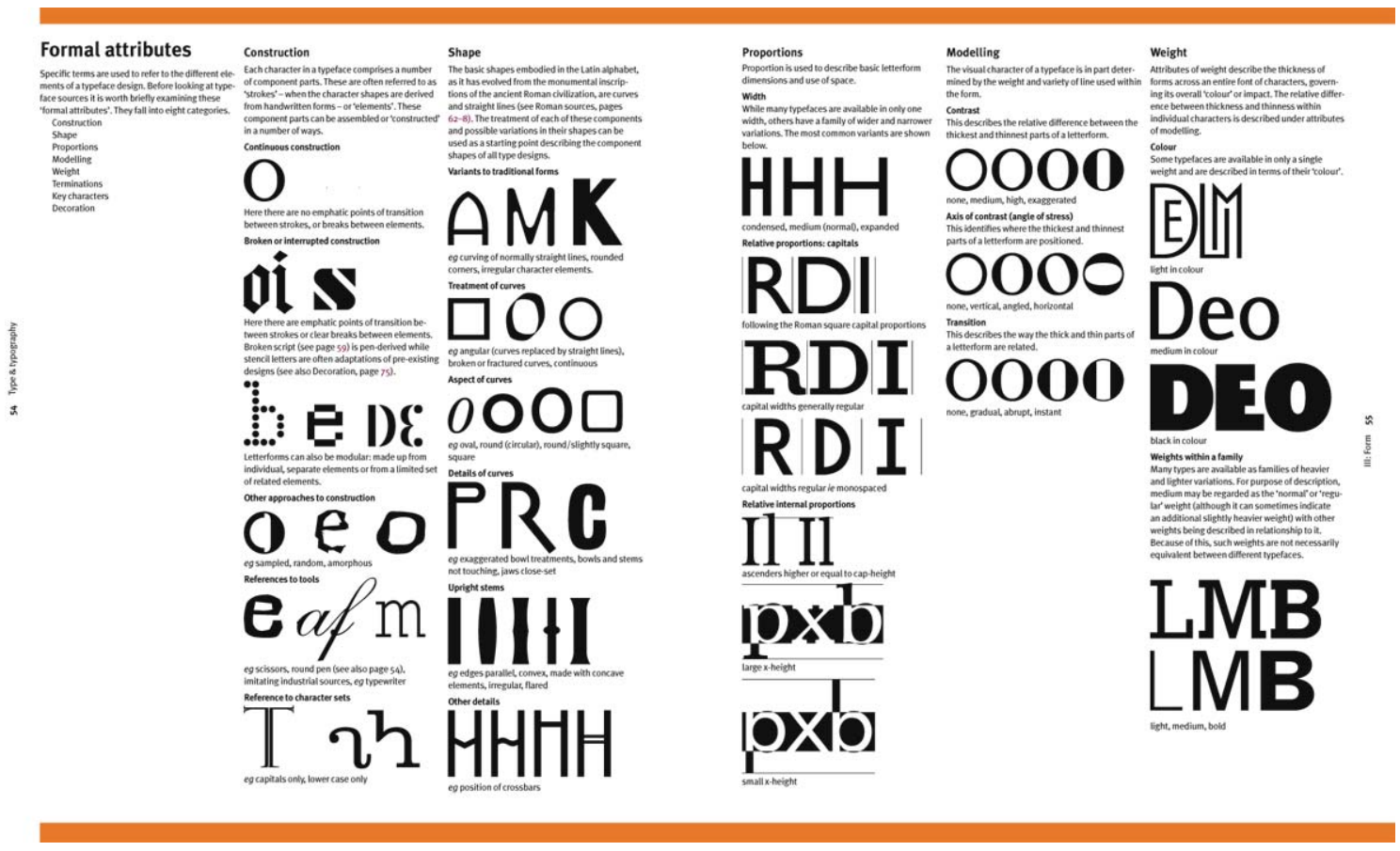

The new description framework operates on the assumption that the formal character of every typeface can be described in terms of its specific configuration of these two components: sources and formal attributes. So, to use the typeface Monotype Old English Text as an example, the relevant source descriptor would be 'handwritten sources' and a list of formal attributes describing the typeface in terms of its very specific formal detail could be written using the identified eight different kinds of attribute headings and sub-menus:

\section{construction}

approach: broken script

structural detailing: non-cursive, upright, non-joining characters and some looping of strokes

direct reference to tool: broad-edged pen

character sets: upper- and lowercase, as a broken script description biased toward lowercase

shape

overall treatment: some character shapes reflect source/ construction influences, emphatically 'cut'

curves: generally angular with square aspect exemplified in an 'o' constructed of six straight sides

stems: (basic) straight with parallel edges

\section{modelling}

as a result of its broken script construction-

contrast: high/exaggerated

axis of contrast: inclined

transition: abrupt

terminals

baseline/general: handwriting-derived oblique rectangular serifs

x-height: as above

ascenders: generally blunt tops, sometimes slightly forked

proportion

letterforms are generally narrow, in addition to which the large $x$-height results in its letterforms appearing generally tall 


\section{Infodesıgn}

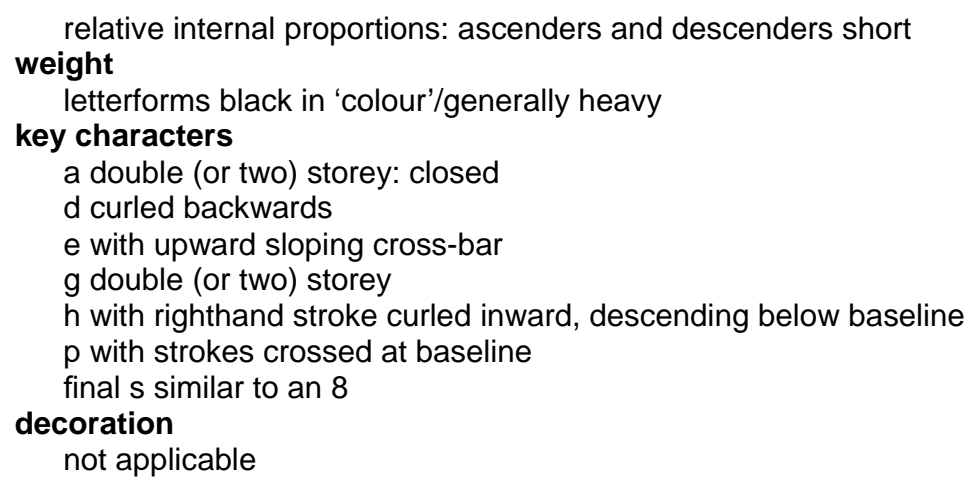

However, while providing the micro level of description so often required, too great an emphasis on differentiation tends to obscure the macro view of a given type's shared formal relationship with others. To abandon the identification of the pockets of formal coherence within groups of typefaces defeats the object of locating the particular within the wider context of type design practice.

For this reason there is a third element in the new framework. Identified as a 'pattern', it lists a recurrent configuration of sources and formal attributes. Generally it is the most common of the possible recurrent configurations of sources and formal attributes that have been selected to be patterns. For formal trends too general to be outlined by use of a specific listings of formal attributes configured as a set pattern reference can also be made to a summary (Figure 5).

PATTERNS [CHRONOLOGICAL OVERVIEW]

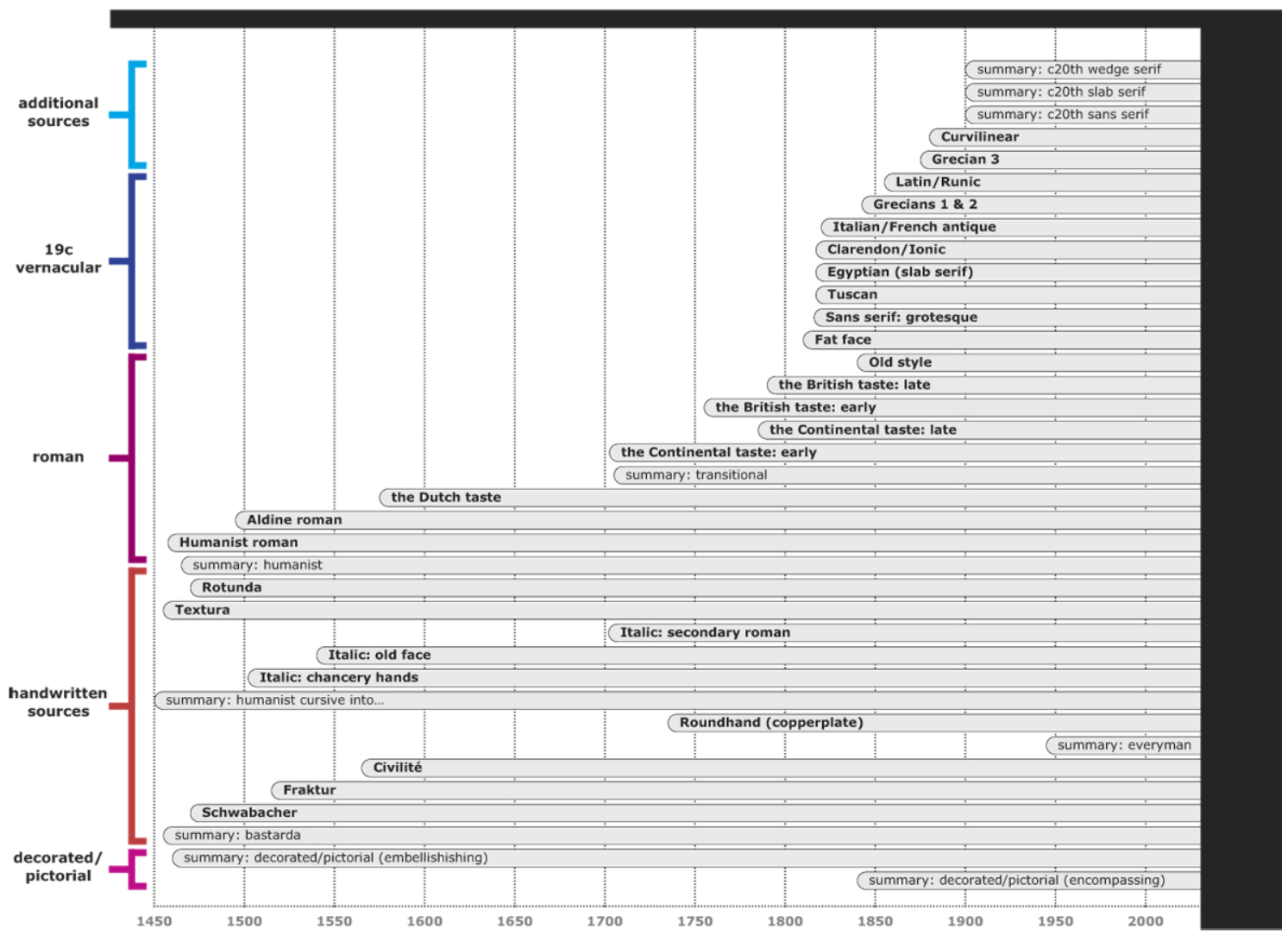

Reference can be made to patterns in the description of a given type, where a strong correlation can be seen between its specific configuration of sources and formal attributes and one or more of these recurrent listings. In the case of the sample type Monotype Old English Text, when reference is made to the pattern definition listings, it is found that the individual listing of appropriate sources 
and formal attributes for this typeface adheres perfectly to the 'textura' pattern (Figure 6)

Figure 6: illustration to demonstrate the basic principles of the new description framework using the sample typeface Monotype Old English

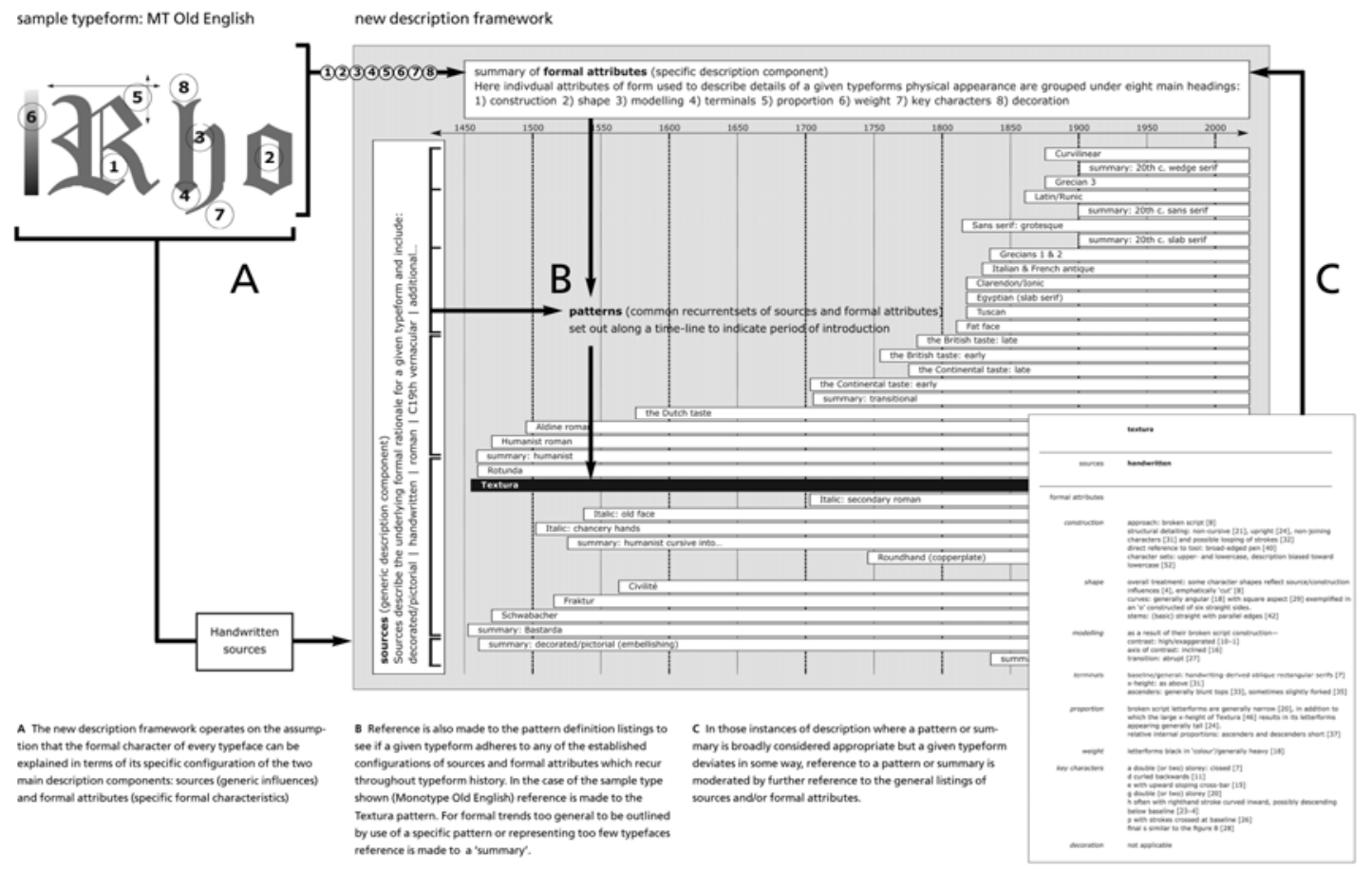

In this way the new description framework operates on morphological principles but is also able to locate key formal types within a historical overview of type design practice. To see it as a purely history-based system is though to limit its scope. Nonetheless the identification and mapping of the 'patterns' description component makes an important contribution to the operation of the framework adding depth and breadth to an understanding of typeform. A profile text is also supplied per pattern qualifying the purely formal descriptor listings with some contextual notes.

The inclusion of this third description component was very much inspired by Nicolete Gray's model for describing change in lettering traditions. She recognized that at points in time, letterforms coalesce around a particular formal idea before moving on [Gray 1960]. Gray was discussing the recurring 'norm' of a particular roman letter in lettering traditions, but her principles of coalescence and divergence around and from given norms are equally appropriate when considering typeforms. In the new description framework 'patterns' represent identified 'norms'. When referring to patterns in the new description framework it is possible to similarly suggest coalescence or divergence from an established 'pattern'. This addresses a primary concern for many who find it impossible to consider 'carving up' a continuum of practice through the use of summary terms.

When using the new framework one of four main description approaches is generally appropriate. The following typeface examples serve in turn to illustrate each of the four possible approaches:

- $\quad$ Pattern only: ITC Bodoni (Figure 7)

The individual listing of appropriate sources and formal attributes for this typeface adheres perfectly to an existing pattern definition, with no need to list any moderating descriptors. A full description of this typeform necessitates reference to a pattern only, in this case, the Continental taste: late pattern. 


\section{Albâtre Babylon Cliché Darmstadt Elletricità Falafel Gefüge Hyacinthus Infidèl Jipijapa Knäckebrot Lullaby Matrimonio Niña Oolong Philosophy Queequeg Ricordo Saucisson Tenet Unsung Vivacious Warsaw Yeomanry Xerxes Yoyo \& Zanzibar}

- $\quad$ Pattern with moderators: FF Disturbance (Figure 8)

The individual listing of appropriate sources and formal attributes for this typeface adheres closely but does not fully match an existing pattern definition, so that additional listing of moderating descriptors is also required. A full description of this typeform necessitates reference to a pattern, in this case, the Aldine roman pattern in addition to a listing of moderating descriptors, see 'additional' sources and formal attributes relating to construction, treatment of shape, proportion and key characters.

aвCDefgHiJkLm

NOPQRStUVWXyz

àáâãååæçèéêëİîĩ

Ñòôõö $\varnothing \propto ß$ Ùû́ü

- Individual typeform description with pattern reference: Bell Centennial (Bold Listing) (Figure 9)

The listing of appropriate sources and formal attributes for this typeface requires individual compilation although reference to a pattern or summary may also be helpful. A full description of this typeform necessitates cross-examination of the typeform against the sources listings - appropriate sources being 'nineteenth century vernacular' and 'additional: technology constraints' - and formal attribute listings to compile an appropriate list of descriptors. Reference might also be made to the information provided in the pattern sans serif: grotesque and summary: twentieth century sans serif. 


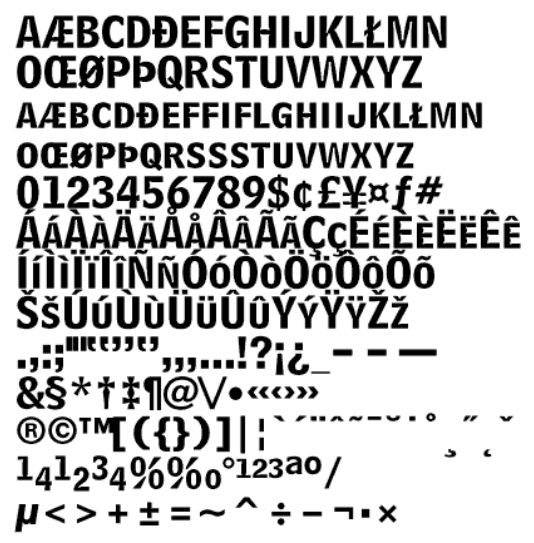

- Individual typeform description: Prototype (Figure 10)

The listing of appropriate sources and formal attributes for this typeface requires individual compilation with no reference to either a related pattern or summary appropriate. A full description of this typeform necessitates cross-examination of the typeform against the sources listings - helpful sources being 'roman' and 'additional: ideas' - and formal attribute listings to compile an appropriate list of descriptors. A key formal attribute construction descriptor listed for this typeform listed would be 'sampled'.

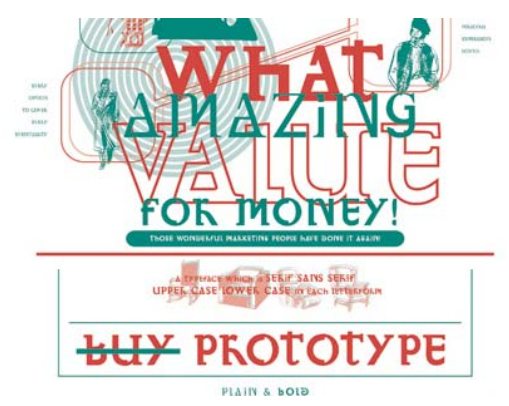

The idea of visual mapping is key not only to the evolution of the new description framework but also to its presentation. As a representation of a chronological history the mapping of the patterns especially serves to show type design practice more accurately as a series of parallel developments rather than, as more typically presented, a purely linear and sequential narrative. Sources and the patterns, which follow each of them, can be colour coded so that while sources are broadly ahistorical as descriptors the point at which use of a given source becomes more prevalent in the field is made visible through the mapping of the colour-matched patterns.

The inclusion of explanatory texts providing contextual information for both source and pattern descriptors, along with the emphasis on a formal attributes listing, which acts as an illustrated glossary of practice, is further evidence of a framework which seeks not only to describe the formal character of every typeface but in the way that it does so, to explain it as well. In the approach followed to typeform description and through an early embracing of complexity in the development process the new framework has departed from the earlier classificatory roles of material organization and management instead evolving into a refined tool for knowledge-building.

Everything about the new description framework - the organisation, utilisation and presentation of its information - enforces the intention that it should constantly reveal how it is working. Description is not centred on an inflexible structure within which typefaces are to be contained, either conceptually or visually. Typefaces can now be brought to the framework, which provides a system of reference against which they can be examined individually and an explanatory formal description built to the requirements of each one. 


\section{Concluding considerations}

Throughout my work emphasis has been upon the description and more latterly on the visual explanation of typeform. That has necessitated exploration of the territory of typeface classification. Existing, if since modified, taxonomies have certainly had their part to play in the development of the new description framework as a means of locating the individual typeform within the broader field. Yet, this relationship of my work to classification is an uneasy one. It is difficult to determine just how far my broader approach has departed from essential classificatory principles? To try and determine whether or not my work is a true classification is though to miss the point. The new description framework fulfils the criteria it was designed to.

My greater concerns in relation to the field of classification lie rather with the negativity associated with the subject in relation to type design. Serious critical discussion is either lacking or limiting, with the classification of typefaces derided as a laughable preoccupation. The type designer John Hudson commented in response to a query about new work in this field,

'I'm sure there are people working on new kinds of typeface classification.

I think it should be formally recognized as one of the great parlour games.' [Hudson 2001]

Part of the general malaise affecting classificatory discussion can be attributed to the temptation to think about the subject universally. Criteria for the scope of the ideal system are too often set out with suggestions based on a perceived need to always be inclusive and embrace for example, nonWestern type or lettering in its entirety. As ideals such ambitions are laudable but practically, the development of such a system lies beyond the capabilities of the individual or indeed, probable circumstance. Classification has then to be discussed in terms of context: who is a given system for and what is its purpose? Once these criteria are established there are grounds for critique. Do the ends justify the means? Without such focussed study and informed critique, discussion either burns itself out, unable to grapple with the implications of the universal system, or becomes lazy.

Another part of the problem is that it is a subject of little consequence for those who know a great deal about type. Often influential voices within the field, the knowledgeable have no need for a strategy to make sense of the subject and will happily consider types on an individual basis mapping new discoveries against extensive internal knowledge banks managed according to an understanding of similarities and difference already assimilated through experience or learned existing organisational structures. At its worst the laziness, which can inhabit discussion results in pomposity. But such pomposity is misplaced. My undergraduate students are overwhelmed and increasingly intimidated by the growing numbers of typefaces available to them. They have little idea of how to make sense of the differences between everything on offer, or what such differences mean in terms of what they might best use in a given design situation.

Recognition of the need to provide user's with better access to ever-expanding font catalogues, especially online, has resulted in growing and often user-determined vocabularies for describing type. These description languages often stand in stark contrast to previous foundry-led vocabularies of type design, which often borrowed heavily from scholarly contexts - with the opportunity for further overlap between marketing and academic study expanded still further by enterprising foundries. During the early part of the twentieth century The Monotype Corporation, for example, had a particular interest in promoting scholarly languages concerning the historical and formal derivations of types within both their general publicity material and marketing tools directed at trade schools to promote the awareness of historically-savvy typefaces pitched as being formally authentic.

Back then the trade contexts for type, were limited, not least, by the tie-in of font sales for proprietary type-setting machinery. Within the current commercial sector, the previously unthinkable has happened - that is the sale of typefaces to those with no trade experience, training or education in any aspect of printing or design practice or scholarship - to people external to the once guarded practices of typesetting and its internal formal vocabularies. And so we are now in a situation where commercial vocabularies, and especially user-determined vocabularies, tend towards an emphasis on subjective description and intended application.

Use is one of the earliest ways of delineating between types - text and display being wellestablished (if now much broader) terms of differentiation, with additional terms such as 'postertype' sometimes suggesting more specific instances of use. Such terms fail though to compare with the extremely specific suggested applications - such as 'wedding' or 'condolences' - which are now being used as terms of delineation in online sales tools [see Linotype Fontfinder].

Yet, such languages are limited in the extreme. For one thing the prescriptiveness of such terminologies surely has implications upon design practice more widely. Are these user-centred 
descriptive categories for typefaces part of a democratic language tool or in fact an example of a vehicle for lowest-common-denominator design ideas, which will result in increasingly bland design outputs?

The highly subjective often formally imprecise nature of use of category headings such as 'sensible' also does little to facilitate transparency in terms of category content with often unexpected discoveries made when using such search terms [see MyFonts]. The employment of significant numbers of terms unrelated to form may in part be a reflection of the increase in type design practice which emphasizes design process as an exercise in intellectual ambition over formal execution but contributes to a fragmentation in the sense of a given type's formal relation to others. The search process itself often prohibits awareness of the field as a whole. While types may be grouped, the relationships between category headings are typically entirely arbitrary. Yet, as I work in this area further so this need to have a sense of the bigger picture seems ever more pertinent.

And as the language of typeform loses consistency and fluency and moves further from that used to articulate previous historiographies in the field so grows the dislocation, identified at the start of enquiry, between understanding of past practice in relation to that of the contemporary scene. Without a living language of continuous practice the danger is that designers will no longer be able to critique past type design practice as a way of invigorating their work in the present - the very premise that saw the establishment of the CLR archive within which this enquiry first emerged. But it is not just about the past. A language of form is needed to be able to consistently and critically discuss type design of all kinds in the present fuelling an ongoing constructive dialogue of practice - a fact recognised back in 1996 by Gerry Leonidas, when he commented,

'I am concerned with designers and educators describing typefaces, shapes on paper or shapes on screen... I am not interested in coming up with computer code; Don Knuth has more than covered this. Think of the difficulties we come upon when we try to describe strange letterforms - Sumner Stone's Informal typefaces or what Gerard Unger calls "synthetic faces". I think there's something there.' [ATypl 1998]

In working in this field it is neither my intention to perpetuate myths of classificatory perfection nor add further to an existing catalogue of abstract discussions. My research is neither prompted by a sense of being tidyminded for the sake of it, nor because I want to outwit the typophiles of the world in working out what Jonathan Hoefler describes as 'the Holy Grail of typography' [Hoefler 1997] Rather I came to this field in response to a practical problem with real implications on the way we write about and teach typographic history and our ability to provide structures for increasing understanding and accessibility to a diversity of typeforms.

I had hoped for a description system, which made visual sense of a subject. And the application of the new framework within pedagogical contexts has been an encouragement [Baines \& Haslam 2005, Clair \& Busic-Snyder 2005]. Though I am interested to see the TypeNavigator tool, which utilizes a similar means of formal interrogation to identify and locate fonts, commercially benefitting FontShop International [Stulle \& Stulle 2004]. This example suggests the potential for application of my framework beyond pedagogy. And perhaps even to contexts beyond typography? I'm sure there are possibilities for using the new framework as a model for use with subjects other than typeforms. Architectural forms maybe? There is also still plenty of scope for refinement. Nomenclature, for example, is an area in need of further collaborative research and review.

The new description framework is not an end in itself, nor as Walter Tracy so rightly points out, should it be [Tracy 1971]. As any other system before it, this framework is a product of its purposes and its time, a summation made at a point in what really needs to be a continuing process.

Especially given that the formal scope of typeface design has not been determined once and for all. It is only a matter of time before new classificatory challenges will appear, and our understanding of typeforms in need of readjustment again. The new framework should not therefore be considered as a complete system. I am well aware that it will need to be added to. And that is where maybe this system does depart from others before it. In trying to overcome the closure characteristic of a 'pigeon-hole' approach to classification, a flexibility has been built into the new framework, to address this issue of change. It was planned that additional description components could simply be added, as needed, and in theory, without undermining existing content. As I review and continue to consolidate my work, I shall find out if that is really true.

\section{References}

ATypl. 1998. 'Annuals and perennials' a discussion of typographic research held at University of 


\section{Infodesıgn}

Reading, 5 November 1996.Type: A Journal of the Association Typographique Internationale 2:1, pp.24-47.

Baines, P; Dixon, C. 2004. 'Letters of reference'. Crafts 186, pp.50-53.

Baines, P; Haslam, A. 2005. Type \& typography. London: Laurence King.

Bartram, A; Dowding, G. 1998 [1961]. An introduction to the history of printing types. London: British Library.

Bauermeister, B. 1994. Manual of comparative typography, The Panose System. New York: Van Nostrand Reinhold.

Blackwell, L. 1998. Twentieth century type. London: Laurence King.

Bringhurst, R. 1994. 'On the classification of letterforms'. Serif 1, pp.30-39.

British Standards Institution. 1967. Typeface nomenclature and classification BS 2961. London: British Standards Institution.

Bullen, H L. 1911. 'Notes towards the study of types'. The Graphic Arts 1:3, p.203.

Carter, S. 1995. Twentieth century type designers. London: Trefoil.

Clair, K; Busic-Snyder, C. 2005. A typographic workbook: a primer to history, techniques and artistry. New Jersey: Wiley.

Dixon, C. 1995. 'Why we need to re-classify type'. Eye 5: 19, pp.86-87.

2001. A description framework for typeforms; an applied study. Unpublished PhD thesis, Central Saint Martins College of Art \& Design, London.

2002. 'Typeface classification'. St Bride Library Conference<www.stbride.org>.

Gray, N. 1938. XIXth century ornamented types and title pages. London: Faber \& Faber. 1960. Lettering on buildings. London: Architectural Press.

Heller, S; Fink, A. 1997. Faces on the edge. New York: Van Nostrand Reinhold.

Hoefler, J. 1997. 'On classifying type'. Emigré 42, pp.55-70.

Hostettler, R. 1949. Type. St Gallen \& London: SGM.

Hudson, J. 2001. ATypl Members online discussion, 1 November 2001.

Kindel, E. 1996. 'The Central Lettering Record'. in Backemeyer, Sylvia (ed.) Object lessons: Central Saint Martins Art and Design Archive. London: Lund Humphries, pp.21-24.

Lawson, A. 1990. Anatomy of a typeface. London: Hamish Hamilton.

Linotype Fontfinder 2008. 'Fonts by themes' <www.linotype.com/51426/themes-start-select.html> date visited 4 July 2008.

McLean, R. 1988. The Thames \& Hudson manual of typography. London: Thames \& Hudson.

Mundie, D, A. 1995. A field guide to the faces. Pittsburgh: Polymath systems, visited 4 July 2008 $<$ http://www.anthus.com/Typography/Faces.html>

Myfonts 2008. 'Font keywords' <www.myfonts.com/keyword/index.html> date visited 4 July 2008.

Perfect, C; Kono, E. 1983. Rookledge's international typefinder. Carshalton: Sarema Press.

Sauthoff, D; Wendt, G; Willberg, H P. 1997. Schriften erkennen. Mainz: Verlag.

Stulle, H; Stulle, R. 2004. TypeNavigator. <http://typenav.fontshop.com> date visited 11 July 2008.

Sutton, J; Bartam, A. 1968. Atlas of typeforms. London: Lund Humphries.

Thibaudeau, F. 1924. 'Classification des caractères d'imprimerie'. in Thibaudeau, F., Manuel Français de Typographie Moderne. Cours d'initation à l'usage de tous ceux que cet art intéresse. Paris: Bureau de l'édition, pp.37-109.

Tracy, W. 1971. 'Type design classification'. Visible Language 5:1, pp.39-66.

Tschichold, J. 1946 [1940]. An illustrated history of writing and lettering. London: Zwemmer. 1952. 'Klassierung und Bennung der Hauptschriften'. In Tschichold, J. Meisterbuch der Scrift. Ravensburg: Otto Meier Verlag. 
Vox, M. 1954. Nouvelle classification des caractères. Paris: Ecole Estienne.

Wallis, L. 1994. 'Typographic chamber of horrors'. Baseline 18, p.45.

Warde, B. 1935. 'Typefaces, old and new'. The Library (fouth series) XVI:2, pp.121-43.

\section{About the author}

Catherine Dixon, studied for her PhD at Central Saint Martins College of Art \& Design, London where she is also a Senior Lecturer in Typography on the BA (Hons) Graphic Design course and a curator for the Central Lettering Record. She is the author of several papers about graphic design, lettering and typography, and co-author (with Phil Baines) of the book Signs: lettering in the environment (Laurence King, 2003). She is also a designer working primarily in editorial design and contributed to the award-winning Penguin Books Great Ideas series. <mail@catherinedixon.co.uk>. 